\title{
APPLICATION OF PEDAGOGICAL CUES FOR TEACHING GRAMMAR IN TECHNICAL HIGHER EDUCATION INSTITUTIONS
}

\author{
USO DE APOIO PEDAGÓGICO NO ENSINO DE GRAMÁTICA EM UNIVERSIDADE \\ TÉCNICA
}

\author{
APLICACIÓN DE APOYOS PEDAGÓGICOS PARA ENSEÑAR GRAMÁTICA EN \\ CENTROS DOCENTES SUPERIORES TÉCNICOS
}

\author{
Elena I. CHIRKOVA ${ }^{1}$ \\ Elena G. CHERNOVETS ${ }^{2}$ \\ Elena M. ZORINA ${ }^{3}$
}

\begin{abstract}
The purpose of the paper is to prove the effectiveness of using pedagogical cues in the form of comic strips, NLP graphics and color when learning the grammar of the English language. The experiment presented in the research (in which 57 students from 17 to 25 years of age participated) proved that grammar rules are comprehended easier, faster, and more effectively if visual cues are used when memorizing the material. A methodology for teaching grammar with the use of comic books was developed as well as the methodological materials for teaching grammar to students of technical higher education institutions. The experiment confirmed that in case of applying the proposed methodology the formation of grammatical skills is $17 \%$ faster and more effective.
\end{abstract}

KEYWORDS: Comic strip. Learning grammar. Pedagogical cues. Visualization.

RESUMO: O objetivo do artigo é mostrar a eficácia do uso de apoio pedagógico na forma de histórias em quadrinhos, gráficos de PNL e cor ao aprender a gramática da língua inglesa. A experiência apresentada na pesquisa (da qual participaram 57 estudantes de 17 a 25 anos de idade) provou que as regras gramaticais são compreendidas de forma mais fácil, rápida e eficaz se o suporte visual for utilizado na memorização do material. Foi desenvolvida uma metodologia para o ensino de gramática com o uso de quadrinhos, bem como os materiais metodológicos para o ensino de gramática a estudantes de instituições de ensino superior técnico. A experiência confirmou que no caso da aplicação da metodologia proposta, a formação de habilidades gramaticais é 17\% mais rápida e eficaz.

PALAVRAS-CHAVE: História em quadrinhos. Aprendendo gramática. Apoio pedagógico. Visualização.

1 Saint-Petersburg State University of Architecture and Civil Engineering (SPBGASU), Saint Petersburg Russia. Professor of the Department of Foreign Languages. Doctorate in Pedagogics. ORCID: https://orcid.org/0000-0003-4307-7211. E-mail: chirkoff@rambler.ru

2 Saint-Petersburg State University of Architecture and Civil Engineering (SPBGASU), Saint Petersburg Russia. Associate Professor of the Department of Foreign Languages. Doctorate in Pedagogics. ORCID: https://orcid.org/0000-0002-2877-6199. E-mail: elena.chernovets@yandex.ru

3 Saint-Petersburg State University of Architecture and Civil Engineering (SPBGASU), Saint Petersburg Russia. ORCID: https://orcid.org/0000-0002-9589-3678. E-mail: zorinaem@bk.ru 
RESUMEN: El objetivo del trabajo es demostrar la eficacia del uso de apoyos pedagógicos en forma de tiras cómicas, gráficos de PNL y colores en el aprendizaje de la gramática de la lengua inglesa. El experimento presentado en la investigación (en el que participaron 57 estudiantes de 17 a 25 años) demostró que las reglas gramaticales se comprenden más fácil, más rápido y más eficazmente si se utiliza un apoyo visual al memorizar el material. Se desarrolló una metodología para la enseñanza de la gramática con el uso de cómics, así como los materiales metodológicos para la enseñanza de la gramática a los estudiantes de las instituciones de educación superior técnica. El experimento confirmó que en caso de aplicar la metodología propuesta la formación de las habilidades gramaticales es un 17\% más rápida y eficaz.

PALABRAS CLAVE: Cómics. Aprendizaje de la gramática. Apoyo pedagógico. Visualización.

\section{Introduction}

Assuming that students of technical colleges mostly have an analytical mindset (technical, analytical, and mathematical mindsets are sometimes used as synonyms), one can assert that their reflexive ability is characterized by a rigid logical structure. It is the mindset that in many respects determines the professional activity of a person. This combination allows one to successfully fulfill the duties, make professional achievements more significant and promote career growth. The analysis of the questionnaires and various kinds of tests offered to students of technical higher education institutions who chose engineering activity, as their future profession, showed that they are able to collect facts, analyze them and build a chain of reasoning that leads to correct conclusions or to the most probable results (DEMCHENKO, 2018).

The analytical mindset is related to associative memory, the ability to create analogies, the ease of working with algorithms or formulae, as well as to the ability to integrate the information received from different areas of knowledge.

The present paper takes into account the fact that scientists refer to (VESNINA, 2018; MALYSHEVA, 2016) that the analytical mindset allows a person to analyze in detail various situations, presenting them as a clear holistic image. As a rule, the thinking processes of such people occur continuously, successfully revealing the essential relationships and connections between the various elements in any information.

Teaching grammar, which is a unity of several systems and subsystems, can be a challenging object of study, because the grammar of each language is arranged in its own way. For example, different languages have different grammatical categories (the category of 
animacy and the category of aspect that exist in Russian, are unknown to many languages, for example English, German and French, but in these languages there is the category of article determination (expressed by two types of articles) that does not exist in the Russian language).

Grammar systems differ not only in grammatical notions, but also in the way these notions are expressed. If one takes into account all these differences, then the grammatical system of each language looks unique. And this means that it can be difficult to study. But the difficulties can be overcome through the use of various methods, including the use of pedagogical cues in the form of comic strips. It is easier to establish an association between the grammatical phenomenon and the visual image (comics) for students who are able to analyze and whose thinking process is based on the logic of reasoning, when the student can transform information using the inference rules (grammar phenomenon $\leftrightarrow$ picture / image / comics $\leftrightarrow$ concept). The result is an idea that is memorized in the form of a structure that establishes the relationship between the symbols (in direct or figurative meaning). With students with a logical mindset, mental processes occur continuously, successfully identifying significant relationships and connections between various elements of information.

The modern stage of the development of teaching a foreign language in technical higher education institutions is characterized by the search for new forms and methods aimed at faster and more efficient learning of foreign educational material. The teaching of grammar has always been in the focus of foreign language teachers. The question of its role and place in the learning process is still relevant. The attitude of the methodologists to teaching grammar has been a determining factor for the methodology of teaching foreign languages, and, consequently, for the methods of instruction. When the grammar-translation method was generally accepted, grammar used to be a priority, and all types of speech activity used to be trained through grammar. The author of English grammar textbooks Tom Hutchinson argued that "solid knowledge of grammar is paramount if students want to use the English language creatively" (THORNBURY, 1999). This idea is repeated by the English grammar methodologist Ur (1999): "There is no doubt that an explicit or implicit knowledge of grammar rules is the basis for language proficiency". According to the figurative statement of V.M. Filatov, grammar is "a skeleton which supports all words. Speech utterances, texts ... are a circulatory system that nourishes a living language, or a foundation on which the building called "Foreign Language" is being erected (PORSHNEVA, 2008).

In the currently dominating communicative approach to teaching, grammar is considered only as a means or a tool for developing speech skills and abilities. This means 
that grammatical phenomena are studied and assimilated as means of expressing certain ideas, communicative intentions of the speaker and extracting information from the speech act. However, the English methodologist Scott Thornbury (THORNBURY, 1999) singled out seven main reasons that make it possible to put the grammatical aspect on the forefront in the process of communicative approach to teaching a foreign language:

1) Grammar is the construction material of speech;

2) Grammar performs an organizing function;

3) The knowledge of grammar prevents from the "fossilization" (or inflexibility) of the speech level of the students;

4) Grammar has instructive nature;

5) Grammar helps to look on language as a structure consisting of isolated grammatical units;

6) Grammar is a system of rules;

7) Grammar helps to meet the expectations of students by making learning more effective.

The teaching of a professionally focused foreign language (such a learning paradigm dominates the teaching of foreign languages in technical education institutions) involves the development and improvement of speech skills through the accumulation of an active and passive lexical minimum, and the means for grammatical processing of linguistic material, i.e. grammatical minimum. The main goal of education is the formation of communicative competence of students who will be able to use a foreign language to solve problems of professional activity and self-education. In accordance with this goal, new directions in the teaching of grammar are being developed since the functioning of any type of speech activity is impossible without a grammatical basis. Linguistic competence, which includes mastering the grammar of the language being studied, is one of the most important components of communicative competence.

The goal of learning grammar, according to Bim (1988), consists in teaching oral speech with concentration on the content of the utterance and the recognition of the grammatical forms while reading and listening with the focus on extracting information. To achieve this goal it is necessary: 
- to consider teaching grammar in a technical education institution not as a goal of teaching a professionally-oriented foreign language, but as a means of mastering speech skills;

- to select the necessary and sufficient grammatical minimum, the assimilation of which will ensure the correct grammatical processing of such types of speech activity as speaking and writing, and, on the other hand, will guarantee comprehension when reading and listening to texts concerning the students' future profession.

\section{Methodology}

The problem of the method of presenting grammatical material is still very relevant. One of the methods for teaching grammar involves the use of pedagogical cues as certain guidelines that motivate students to concentrate their attention on the essential, eliminating the uncertainty, which leads to the reduction of the number of mistakes. Elements of NLP graphics (arrows, highlighting, font, color) and comics, which are closely related to infographics in the form of using visual communication tools, can be used as such pedagogical cues.

Developing methods and techniques of teaching grammar, it is necessary to take into account the learning conditions, which primarily include the psychological characteristics of the age group of students, their average age being 17-25. Students of this age are not inclined to mechanical memorization, but try to present their thoughts in clear forms and comprehend the material, establish various connections, analyze and synthesize new material. The teacher has to support and develop this feature of cognitive activity of adult learners. At this stage of their psychological development, it is very important to apply visual generalization of the studied grammatical material in the form of diagrams, tables, figures, highlighting, graphic elements and other ways of schematized presentation of grammar. A comic strip can be one of such mixed (both verbal and nonverbal) pedagogical cues that help visualize the grammatical material.

It should be pointed out that at present comics are often used at school, including a foreign language classes (KAPUSTINA; DIKOV, 2018). Highlighting the basic idea of information security, A.A. Kapustina and A. V. Dikov focus on the possibilities of using comics in the practice of working with new vocabulary, when students can come up with comic stories using the vocabulary they are studying. Schoolchildren are taught to create comic book heroes who speak a foreign language. Thus, it is necessary to formulate their 
thoughts in English. At the same time, students should fill out the forms of dialogues for different comic book characters, which helps to develop the skills of dialogic communication and studying the structure of the language in a certain context. In addition, they master the skills of writing, reading and narrative.

Williams (2008) speaks about the importance of comics in teaching, arguing that comics are powerful learning tools. Students and teachers can use comics to study personal experiences in the form of stories. Wilson (2005) agrees that using comics is a way to cross the borders between visual culture and the classroom.

Williams (2008) says that there are at least three reasons why comic books can be useful learning tools:

1) this genre is interesting for students;

2) comics are inexpensive;

3) the vocabulary is not complex, comics are easy to read and understand (WILSON, 2005).

The most important moments in training are related to the fact that comics create opportunities for teachers to involve students in important discussions, for example, about visual perception, writing, history of the language, etymology of words and the content of texts at different levels (BERKOWITZ; PACKER, 2001).

Teachers who skillfully use comics in their work provide students with many opportunities for deconstructing these texts at several levels. This multilevel deconstruction can include studying the history of the country of the studied language, the origin of some word, the intention of the creator of the comics, the character of the comic book hero and the context of what is happening, as well as finding the relationship between the words and images of the comics.

Although words and images are elements of comic texts, the main thing in the process of perception is reading. It is usually more convenient for students to decode (read) the visual system of letters and words. Pairing visual images with words is an easy way to help students develop stronger visual literacy.

Comics provide an opportunity to carefully study the way interdependent images and words create a consistent story. As with looking at a work of art, the reader can decide where to start and how long to look at this or that part of the comics. Students can first look at words, read a phrase in a speech bubble, look at images, or go directly to the next page. 
The work of R. Williams confirms that comics is a powerful way for learners to imagine the future, understand historical events, make up their own stories, develop a sense of empathy, and decode images, matching visual keys and text.

According to R. Williams, comics is an innovative way to work with visual culture in the audience. Comics can initiate a wide range of interdisciplinary discussions and direct students' work on various issues. Comics is also a tool that helps teachers to work with inactive students.

In the sources mentioned above, comics was regarded as a tool for work, first, with the school audience for information security education and, secondly, with the student audience in art classes. The present article is about teaching grammar to students of technical universities using comics, combining the visual and text culture of a foreign language into a single concept.

This special organization of teaching grammar of a foreign language transforms the process of mastering the grammatical side of speech into a rational and meaningful one. In addition, a significant proportion of students have a specific "taste" in education. Interesting classes with elements of technology of edutainment (education combined with entertainment) increase the learning motivation and help to focus on one grammar issue longer. Visual saturation of pedagogical cues makes such classes bright, convincing and contributes to the intensification of the learning process, influencing several types of memory at a time: visual, auditory and emotional.

The explanation of grammatical rules must take into consideration the verbal-logical type of thinking typical for 17-25 year old students. It means that the grammar rules should be explained on the example of comparison of the studied and native languages. An adult learner can logically comprehend a specific example and transfer it to similar situations, that is, the development of grammatical phenomena occurs in an inductive way, from the particular to the general. The explanation of the grammar material should be accompanied by exercises containing the known lexical material in accordance with the "microtopic" concerning the future profession.

Vitlin (1978) speaks about the need to reduce the amount of general grammar terminology as compared with the information contained in the grammar reference books.

So, the optimal solution to all the problems discussed above can be found in the assumption that the process of forming a foreign communicative competence in a technical education institution should be carried out using less grammatical material than presented in grammatical reference books, i.e., using the selected grammatical minimum. 
A different point of view is expressed by Yasyukova (2005). She argues that the increase in training time and the use of supposedly innovative technologies did not provide either a quality primary education or the mastering of the most complex areas of modern knowledge (in particular, foreign languages). According to Yasyukova (2005), the main thing in the educational process is the development of conceptual thinking, which promotes the development of social intelligence, tolerance, forms an adequate self-esteem and positive communicative attitudes, optimizing the sphere of communication. Conceptual thinking also stimulates the development of various abilities (linguistic, mathematical etc.). As a result, emotional stress is removed in the process of study, self-reliance and educational motivation are formed. Conceptual thinking triggers the development of creativity, contributes to the formation of positive values, legal and civic consciousness.

Children usually transform scientific knowledge into a familiar visual shape, which cannot express and present objective scientific laws. These laws have to be simplified and the resulting knowledge is neither objective nor scientific. Schoolchildren, and then students, while figuratively perceiving information, continue to exist intellectually in pre-school childhood. They are expanding the system of representations, but the ways of perception and processing of information are not being improved.

If a child studies science and subsequently masters the methods of scientific thinking and problem solving, then he or she gradually develops universal skills as a higher level of abstraction or singling out a general algorithm of activity that is the same for all spheres of knowledge (DUBROVIN, 1992). An objective analysis of the situation, the isolation of causeeffect relationships, the forecast of the development of events is impossible without the logic of conceptual thinking.

Universal learning activities are skills that are formed on the basis of conceptual thinking. They are formed in the process of the study of sciences by abstracting general analytical operations, and then used in any activity, including practical. Yasyukova (2005) believes that the study of a foreign language must begin with a full course of grammar, the basis of which is the formation of concepts. This is an historical process of collective learning of objective laws of nature and society. When a person hears a definition or sees the formula for the first time, he gets acquainted only with a shell, sound or visual image, which is perceived as a kind of holistic impression, though there is still nothing behind it. He cannot retell in his own words the rule he just learned, neither can he see what formulas should be used in a given problem until he turns these visual images into concepts. 
This becomes possible only in the process of usage. When a student, while solving problems or performing various exercises, uses formulas and rules, then he or she establishes their connections with concepts, defines the scope of their application and specifies their meaning. Only then symbols and words are filled with meaning. Only gradually in the process of usage, formulas or rules, combined with personal, internal experience, will be filled with concrete content, become understandable, and start being used by one's own decision and correctly, and not simply be reproduced from memory. That is why first goes the study of conceptual grammatical material, and then its practical use.

This process was called by Vygotsky $(1982 ; 1983)$ the concept development law. When the concept develops, the essence, the inner meaning (the objective principle) that "sprouts" (is built in as a cell) into the "conceptual grid" or the "conceptual pyramid", abstracts from the word, definition or formula and occupies a certain place in a united multidimensional coordinate system among equivalent, more general and more specific concepts.

The authors of the present article share the view of Vitlin (1978) and other researchers such as Gez et al., (1992) about the need to study less grammar material than is given in the grammar reference books. This is due, above all, to the scarcity of study hours, traditionally devoted in non-linguistic technical universities to foreign language classes.

Let us dwell in more detail on the methods of presenting and fixing the selected grammar minimum. It seems rational to do this using pedagogical cues in the form of diagrams, drawings and comics, as well as other graphic means, such as signs, geometric shapes, highlighting, the use of different colors and fonts, and text boxes.

The use of pedagogical cues makes the learning process both cognitive and interesting. Foreign Methodists believe that the use of such mixed cues as comics contributes to the development of critical thinking, understanding of humor and is a trigger for the formation of grammatical skills (OLIVERI, 2018; SPITALNIK, 2018). It is important that assignments should be related to the topic of the lesson, and the level of tasks should be differentiated so that they can be solved by every student. In particular, the use of mixed pedagogical cues in the form of comics helps to solve this problem. Today's teens who are not inclined to attentive, thoughtful reading of grammar rules are not afraid of 2-3 lines of text illustrated with funny pictures.

The need to take into account the fact that most young people now have so-called "clip" thinking led to the creation of a number of grammar textbooks that lack detailed rules and where explanations are given in the form of funny drawings and comic strips. A bright 
example is grammar textbooks by Dubrovin (1992) and Popovets (2015) as well as the "Happy English" textbook for schools (KLEMENTEVA; MONK, 1993). Educational comics became an integral part of the English-speaking culture and were first used in the last century in textbooks by Eckersley (1992). Now, they are used, for example, in "Active Grammar" textbook (DAVIS, 2012). On the other hand, comics is an international phenomenon, as can be seen from the example of the well-known French textbook for adult learners, "Le Nouveau Sans Frontières" (DOMINIQUE et al., 2002), where comics goes on like a story through the whole book.

However, in addition to printed sources, grammar in the form of comics can be also found on the Internet, which means that learning also takes place with the help of information and communication technologies (ICT). The most famous online tutorial - Grammarman (Grammarman Comic: http://grammarmancomic.com) was created by an Irish English teacher Brian Boyd. The unusual nature of this resource lies in the fact that the visual perception of the comics is also supported by the audio.

The illustration below shows the screenshot of the main page of this resource.

Figure 1 - Screenshot of the main page of the Grammarman online resource

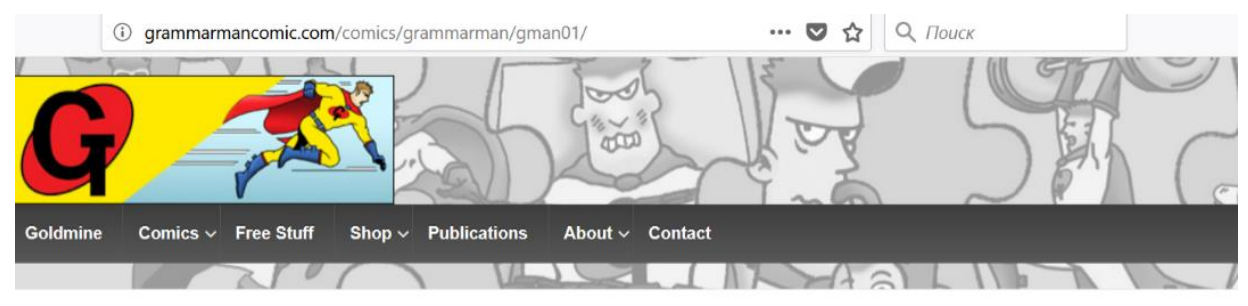

Introducing Grammarman

You can listen while you read.
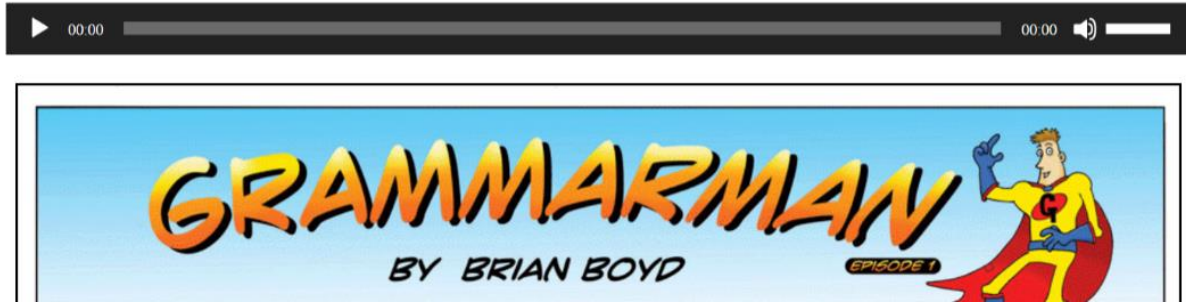

Source: Authors' collection

Now let's move to the definition of the comics and its place in the learning process. According to Anisimova (2003), "a creolized text is a complex text formation in which verbal and non-verbal elements form one visual, structural, semantic and functional whole, aimed at a complex impact on the addressee". This definition helps to define comics both as a mixed 
pedagogical cue and as a kind of creolized text. That's why one should distinguish comics from a set of pictures illustrating the plot. It is a fact that educational motivation is higher when working with a mixed cue (comics) than with a non-verbal cue (image).

\section{Results}

Comics can serve both as a source of grammar knowledge, and as a basis for doing grammar exercises. For example, typical tasks might be to fill in speech bubbles, restore a dialogue, or restore the storyline. Brian Boyd offers not only to use readymade comics, but also to create such cues. However, he draws attention to possible negative aspects that may arise when working with comics. For example, incomplete inclusion of all students in the work, minimal English and simplified grammar, the wrong order of dialogical utterances. On the other hand, in the text of the comics, such stylistic means as epithets, metonymy, metaphorical comparisons, onomatopoeia, alliteration and repetitions, "speaking names", phraseological units, vocabulary of various registers are widely used. Such abundance of expressive means opens a great perspective for creativity of teachers and students.

The authors of the present paper have conducted an experiment on using comics as a pedagogical tool for teaching grammar. The participants of the experiment were two mixed male and female groups, one of which was a control group, and the other an experimental group (total of 57 people).

At the first stage, a standard starting test was conducted and both groups showed approximately equal knowledge of grammar material. Then, a new grammar topic was delivered as a lecture to the control group without the use of pedagogical cues, while in the experimental group working with comics was introduced. Already at the theoretical stage, the increase in the educational motivation in the experimental group was noticeable, as the students demonstrated less anxiety and more interest.

At the second stage, it was necessary to train the grammar material with the help of exercises. In the control group, the exercises contained only the text with the missing spaces that needed to be filled with appropriate grammatical forms, and in the experimental group the exercises were also presented in the form of a comic strip with spaces inside the speech bubbles. The experimental group did an identical amount of exercises $10 \%$ faster than the control group and showed a 23\% higher result. A survey in the experimental group showed that the images in the comics and the relation of the plot with the images provided significant help in completing the assignment. 
At the third stage, the trainees were asked to create an exercise on a grammatical subject by analogy with the exercises they had performed. In the control group, the text template limited the development of creative thinking, and the lack of vocabulary did not allow to create high-quality works. In the experimental group, the students were offered the option of creating a comics on paper or using a special computer program (Comic Life, Create a Comic, Make Beliefs Comix, Creaza Cartoonist). Having artistic abilities was not essential. All the work on the comic was conducted according to the method described by Brian Boyd in the webinar "Using comics and superheroes to teach grammar" from Macmillan (BOYD, 2018) and using the "Write and Draw Your Own comics" tutorial (STOWELL, 2014). In Boyd's view, there are 3 stages of the process:

- Stage 1 Getting started

- Generating the interest

- Introducing the project

- Stage 2 Initial ideas

- Research

- Feedback

- Creating the characters and their world

- Stage 3 Making the comic

- Scripting and storyboarding

- Drafting and redrafting

- Making and publishing the finished pages.

Brian Boyd also explained how to work with comic elements, such as interaction, sound effects, thoughts, captions, text on a screen.

The illustration below shows the comic elements and their names. 
Figure 2 - The comic elements as given in the Grammarman online resource

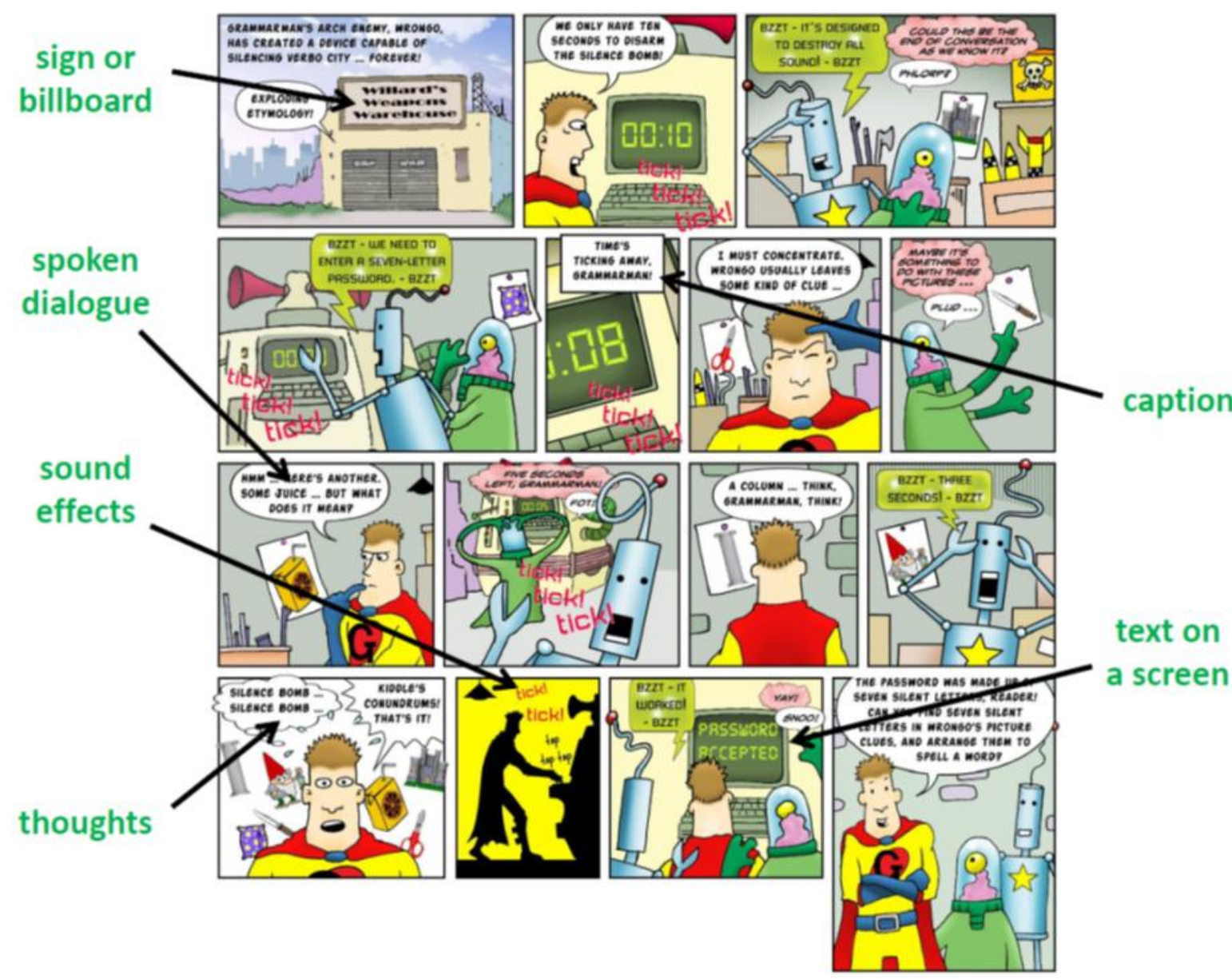

Source: Authors' collection

The process of creating one's own comic strip has turned into a fascinating project. The exchange of comic books allowed the students to repeat the grammatical subject they studied, having a variety of types and qualities of visual and verbal supports. Students preferred to use special computer programs to create comics in order to make images look good, and only $12 \%$ began to draw comics on paper. A survey of the members of the experimental group showed that they liked the task and they would like to see it the form of a creative educational contest. In addition, at the stage of feedback, all possible problems that could arise, according to Boyd (2018), in the process of creation were discussed. The list of problems is as follows:

- One student works, and three others just watch.

- Overly complex / "ambitious" stories.

- Excessive use of captions / bubbles.

- Unwillingness to correct the drawing.

- Use of the native language. 
- Colored speech bubbles.

- Wrong order of replies in the dialogue.

- Very short text.

- Too many panels on the page.

- Simplified English.

- Drawing at the edge of the paper.

- Inappropriate content / bullying.

The fourth stage was reflection. In both groups, the same control test was carried out, consisting of two parts: the first - a text, and the second - the comics. As a result of the analysis, it was revealed that the total score for the test in the experimental group was $21 \%$ higher than in the control group, while with the second part (containing the comics), both groups coped better than with the first.

A week later the test was repeated and revealed that the actualization of knowledge in the experimental group was $17 \%$ higher, which makes it possible to make a conclusion about the advisability of using such a mixed medium as educational comics.

Initially, when dividing the participants into a control and experimental group, the representative systems of the students were not taken into account, although according to the well-known methodologist Harmer (2015) this is very important for a full-fledged educational process. In Russian pedagogy it is common to divide students through the channels of perception of information into visual, auditory and kinesthetic learners, and in the neurolinguistic programming there is the term VAKOG, which is the acronym of 5 representative systems: Visual, Auditory, Kinaesthetic, Olfactory, Gustatory. Working with the comic book helps to fully interact with students with any way of information perception. Thus, for kinesthetic learners it is easier to work with tools not on the computer, while auditory learners also act out the proposed dialogues or listen to the text (as on the site of Brian Boyd). Perhaps, it was the lack of diversity of information perception channels (which better presented in the comics) that prevented the control group from successfully solving with the proposed tasks.

According to Murtazaeva (2012), the tools of education are the materials of the educational process that help the teacher to organize effective instruction in a foreign language, and the students to effectively master it. Undoubtedly, comics can be considered not only a mixed pedagogical cue, but also a progressive means of teaching foreign grammar. 
Thus, comics are graphic and other images that are combined in a certain way, designed to convey information and / or to evoke in the viewer (reader) an aesthetic response (McCLOUD, 2016). A visual form of representation simplifies the perception of the information, but makes it difficult to perceive a large information segment. Serving as a form of pedagogical cues at the beginner level of studying grammar material, comics can express and show objective language laws, which at the first stage of learning have to be simplified. Then the used pedagogical cues should be changed or removed, so as not to become redundant, not allowing the student to independently construct phrases, sentences, and texts in a foreign language.

The use of pedagogical cues (first of all comics) in teaching the grammatical side of speech serves two purposes: presentation of the grammatical form of the phenomenon being studied and demonstrating its use in speech. Thus, the principle of communicative methodology is realized: grammatical phenomena are studied and learned not as abstract structures, but as means for expressing one's own ideas during the formation of speaking and writing skills, as well as means of recognizing the grammar forms when reading and listening to texts created by other authors.

Pedagogical cues are especially important in the study of those phenomena of the grammar of a foreign language that do not coincide with the grammar of the Russian language. Within the selected grammatical minimum, these cases are the use of the article, the presence of a ramified system of grammar tenses, auxiliary verbs, constructions with nonpersonal forms of verbs, the use prepositions that does not coincide in Russian and English, and the conversion of nouns into verbs.

Since the study of grammar in a non-linguistic technical university is subordinated to the task of forming the skills and abilities of all types of professional speech activity, this process must be built with the focus on the selected lexical material. This leads to the use of a limited number of pedagogical cues from modern grammar textbooks, since they are developed on the basis of general vocabulary. It is advisable to involve students who have a higher level of linguistic competence than others into developing pedagogical cues on the lexical material of the language of the future profession. Such projects can also be special grammatical educational comics created both on paper and with the help of ICT tools.

Despite the fact that in the Russian educational space there are practically no methods of using comics and it is difficult for teachers to understand the merits and demerits of the genre and its specifics, to say nothing of its didactic potential that has been successfully used for many years in the educational systems of many countries of the world, the authors of the 
present paper believe that educational grammatical comics can become not only a popular mixed pedagogical cue, but also a useful tool that increases the educational motivation and speed of the formation of knowledge, skills and abilities

\section{Conclusion}

Thus, the study of grammar in a non-linguistic technical education institution should be regarded as one of the means of forming a foreign communicative competence. The study should be subject only to a carefully selected grammatical minimum. The use of pedagogical cues in the study of grammar has made it possible to reduce the time for memorizing grammar structures by $10 \%$, to increase the motivation and activity of students, to diversify and facilitate the learning of the grammar structures of a foreign language, as well as to contribute to a deeper understanding of the grammatical phenomenon studied, as shown by the experiment. This effect was achieved by the use of the visualization method in the form of comics, elements of NLP graphics and color. The application of the method described in the article made it possible for students to develop strong grammar skills serving the communicative purposes of instruction.

ACKNOWLEDGMENTS: We express our gratitude to the top management of SaintPetersburg State University of Architecture and Civil Engineering and personally to the vicepresident for academic affairs, D.Sc. (Pedagogy), professor I.R. Lugovskaya, head of the Department of Foreign Languages, Cand. Sc. (Pedagogy), associate professor M.V. Protsuto for support and assistance in the work, as well as to all the students who took part in the experiment.

\section{REFERENCES}

ANISIMOVA, E. E. Linguistics of the text and intercultural communication (on the basis of creolized texts). Moscow: Academia, 2003. 128 p.

BERKOWITZ, J.; PACKER, T. Heroes in the classroom: Comic books in art education. The Journal of Art Education, v. 54, n. 6, p. 12-18, 2001.

BIM, I. L. Theory and practice of teaching german in high school: problems and prospects. Moscow: Enlightenment, 1988. 256 p. 
BOYD, B. Using comics and superheroes to teach gramar. Available:

http://www.macmillanenglish.com/events/using-comics-to-teach-grammar/. Access: 15 Jan. 2018.

DAVIS, F.; RIMMER, W. Active grammar. Level 1. Cambridge University Press, 2012. 200 p.

DEMCHENKO, E. Distinctive features of students of technical universities. TM student, 2018. Available: http://tmstudent.ru/article/otlichitelnyie-chertyi-studenta-tehnicheskogovuza. Access: 15 Jan. 2019.

DOMINIQUE, P. et al. Le Nouveau Sans Frontières 1. Nouvelle Edition. Cle International, 2002. $224 \mathrm{p}$.

DUBROVIN, M. I. Illustrated guide to English grammar. Express course. Moscow: StartPress, 1992.224 p.

ECKERSLEY, C. E. Essential English for foreign students. 1992. 336 p.

GEZ, I. I. et al. Method of teaching foreign languages in secondary school. Moscow, 1992. $412 \mathrm{p}$.

GRAMMARMAN Comic. Available: http://grammarmancomic.com. Access: 15 Jan. 2019.

HARMER, J. The practice of english language teaching. Longman, 2015. 446 p.

KAPUSTINA, A. A.; DIKOV, A. V. Training of information security with the help of comics. Publishing house "Education and Informatics". Available:

http://infojournal.ru/product-informational-safety/. Access: 01 Dec. 2018.

KLEMENTEVA, T. B.; MONK, B. Happy English. Book. 1. Textbook. for grades 5-6. Moscow: Education, 1993. 416 p.

MALYSHEVA, A. D. Influence of the type of personality and thinking on the educational activity of students (on the example of learning foreign languages). Pedagogy and

Psychology: Trends and Development Prospects, Volgograd, n. 3, p. 76-79, 2016

MCCLOUD, S. Understanding the comics. Invisible art. Moscow: White apple, 2016. 216 p.

MURTAZAEVA, M. M. Modern methods and technologies of teaching foreign language and literature in school and university: monograph. Volkhov: Izd-vo Lema, 2012. 78 p.

OLIVERI, D. Cartoon drawing in the classroom: ways to use cartoons in teaching. Available: http://homeschoolcurricula.suite101.com/article.cfm/cartoon_drawing_in_the_classroom. Access: $01 \mathrm{Dec}$. 2018.

POPOVETS, M. A. English in comics. Moscow: Eksmo, 2015. 320 p. 
PORSHNEVA, E. R. Grammatical concepts and methods for constructing them in the study of a foreign language (on the material of foreign studies). In: PORSHNEVA, E. R.;

SPIRIDONOVA, O. V. Foreign languages at school. 2008. n. 6, p. 73-77.

SPITALNIK, I. Cartoons in the classroom. 2018. Available:

http://s3.amazonaws.com/powtoon/books/Cartoons-in-the-Classroom-Book. Access: 01 Dec. 2018.

STOWELL, L. Write and draw your own comics. Usborne Publishing Ltd, 2014, 102p.

THORNBURY, S. How to teach grammar. Edinburgh: Pearson, 1999. 189 p.

UR, P. Grammar practice activities. A practical guide for teachers. New York: Cambridge University Press, 1999. 148 p.

VESNINA, T. What is your mentality? Available: http://www.greenmama.ru/nid/2207139/. Access: 01 Dec. 2018.

VITLIN, J. L. Learning adults in a foreign language. Questions of theory and practice. Moscow: Pedagogy, 1978. 165 p.

VYGOTSKY, L. S. Collection of works in 6 volumes. Moscow, 1982. 504 p. v. 2.

VYGOTSKY, L. S. Collection of works in 6 volumes. Moscow, 1983. 369 p. v. 3.

WILLIAMS, R. Image, text, and story: comics and graphic novels in the classroom. Art education, 2008. p. 13-19.

WILSON, B. More lessons from the superheros of J.C. Holtz: the visual culture of childhood and the third pedagogical site. Art Education, v. 58, n. 6, p. 18-24, 2005.

YASYUKOVA, L. A. Regularities of the development of conceptual thinking and its role in teaching. Saint Petersburg.: IMATON, 2005a. 256 p.

YASYUKOVA, L. A. The role of conceptual thinking in teaching. Bulletin of Practical Psychology of Education, v. 1, n. 2, p. 22-29, Jan./Mar. 2005b. 


\section{How to reference this article}

CHIRKOVA, E. I.; CHERNOVETS, E. G.; ZORINA, E. M. Application of pedagogical cues for teaching grammar in technical higher education institutions. Rev. EntreLínguas, Araraquara, v. 7, n. esp. 2, e021009, 2021. e-ISSN: 2447-3529. DOI: https://doi.org/10.29051/el.v7iesp.2.15135

Submitted: 05/01/2021

Required revisions: $26 / 02 / 2021$

Approved: $24 / 03 / 2021$

Published: 01/06/2021 